\title{
Traumatic Extradural Hematoma - Our Comparative Experience between Conservative and Surgical Management in Rural India
}

\author{
Subodh P Ugane ${ }^{1}$, Hamza Qazi ${ }^{2}$ \\ ${ }^{I}$ Dr Subodh P Ugane, MS(General Surgery), Assistant Professor, Department of General Surgery, GMC Miraj. \\ Correspondence address: Teachers Quarters, Civil Hospital, And Sangli-416416 Dist: Sangli, Maharashtra, \\ INDIA. \\ ${ }^{2}$ Dr Hamza Qazi, PG candidate, MS (General Surgery), Department of General Surgery, GMC Miraj. \\ Correspondence address: Room no 38, IHR Hostel, Civil Hospital, Sangli-416416, and Dist: Sangli, \\ Maharashtra, INDIA.
}

\begin{abstract}
Background: To study and compare the role of conservative management and surgical intervention in traumatic extradural hematoma $(E D H)$ in rural India.

Setting: Government Medical College, Miraj, Maharashtra state, India.

Materials and methods: 240 trauma patients diagnosed as extradural hematoma on CT scan were managed during 2 year period.

Outcomes: Comparative role of conservative management and surgical intervention were studied.

Results: Out of these 240 patients admitted 134 were managed conservatively, 106 cases were operated upon. 62 were operated upon immediately and 44 were operated upon as delayed. There were 2 deaths and 8 had poor outcome in this group of patients.

Conclusion: It is stressed that small size $<10 \mathrm{ml}, \mathrm{GCS}>12$ and locations other than temporal area are the criteria for conservative management. 44 patients out of 178 were needed to be treated surgically during the course of conservative management due to neuro deterioration, increase in size of hematoma on CT, bradycardia, hemiparesis, pupillary abnormalities, delay in referral and only $18 \%$ had poor outcome. A strict vigilance is to be kept for clinical deterioration and various reasons mentioned above are to be kept in mind and patients should be subjected to repeated CT scan. Early diagnosis and immediate surgical intervention had good outcome, which shows the rewarding results of early diagnosis and intervention.
\end{abstract}

Keywords: Conservative management, Extradural hematoma, Head injury, Surgical management.

\section{Introduction}

Extradural hematoma (EDH), considered to be the most serious preventable complication of head injury, requiring immediate diagnosis and surgical intervention, encountered in $2 \%$ of patients with head injuries and $5-15 \%$ of patients with fatal head injuries, is a traumatic accumulation of blood in the potential space between the inner table of the skull and the stripped off dural membrane [1], prognosis is considered excellent if treated aggressively. EDH usually is stable, attaining maximum size within minutes of injury, a hypothesis some authors disagree with[2]. However it may progress during first 24 hours after injury. Re-bleeding or continuous oozing presumably causes this progression. Occasionally EDH runs a chronic course and is detected only days after injury. A patient with small EDH may be treated conservatively through close observation is advised, as delayed, yet sudden neurological deterioration may occur. Though surgical evacuation constitutes the definitive treatment of this condition but many patients can be saved from craniotomy with watchful repeated neurological assessments. Aim of our study was to study the comparative role of conservative management and operative intervention during the management of traumatic EDH.

\section{Methods}

A prospective comparative study of traumatic EDH treated conservatively and surgically was done over a period of 2 years in Government Medical College, Miraj \& PVPGH, Sangli from 01-07-2010 to 30-06-2012. Our study included only patients diagnosed as EDH after CT scan. Cases with associated cerebral lesions were also included, but only if the relevant lesion was the extradural hemorrhage. The first clinical assessment was made in our trauma unit on admission.

Initial resuscitation efforts included ABC- assessment and stabilization of Airway patency, Breathing and Circulation. A thorough trauma evaluation was done. Detailed history especially about mode of injury, lucid interval and the physical examination included a thorough evaluation for evidence of traumatic sequelae and associated neurological deficits, skull fractures, hematoma, lacerations, bradycardia, hypertension, CSF 
Traumatic extradural hematoma - our comparative experience between conservative and surgical otorrhoea or rhinorrhoea, hemotympanum, GCS score, muscular weakness, aphasia, visual field defects, numbness, ataxia and level of consciousness. Repeated neurological examinations were done to assess the development of raised intracranial pressure. Apart from routine laboratory investigations relevant radiological imaging studies were done. This study was done by dividing patients with EDH into groups according to different clinical parameters and treatment modalities and neuro-radiological findings at the time of admission and hospital stay. Group-A: who required immediate surgical evacuation of the hematoma. Group-B: was further divided into two: B-l, patients who were treated conservatively. B-2, patients who were well with initial conservative treatment despite visible EDH on the first CT scan and who required surgery in the course of conservative management and delayed appearance of EDH on CT scan.

Neurological evaluation was immediately undertaken following cardiopulmonary resuscitation, skull and chest X-ray, if time permitted. CT scan head was done in all patients. The dehydrating agent Mannitol, cerebro-protective agent Citecholine and anti-convulsive agent Phenytoin sodium were given in certain cases that had associated brain injury, edema, convulsion, threatening to coma. Dexamethasone was administered for first few days and then gradually tapered off. Conservative management was immediately terminated and a craniotomy performed if the patient showed signs of localized brain compression or herniation.

Outcome was measured according to Glasgow outcome score by Jannett and Bonds criteria, which include death, vegetative state, severe disability, moderate disability and good recovery. A moderate disability who recovered independence (GOS-3, 2 and 1) were considered to have a good outcome, whilst patients who were severely disabled, vegetative, moribund or died were included together in the poor outcome group. The distribution of good and poor outcome with respect to each of the prognostic factors was examined statistically using a Chi-square test [3].

\section{Results}

Out of these 240 patients admitted, Table 1 shows various reasons for delayed operative intervention in 44 patients with neuro-deterioration being the commonest reason involving eighteen patients. Eight located at temporoparietal, 4 each in temporal and parietal, 2 in occipital region, followed by delayed development on CT, 2 each in frontal, parietal and temporoparietal region. Pupillary changes and hemiparesis were seen in 6, located in temporoparietal region. Increasing bradycardia was reason in 4 located at temporal and occipital region and persistent vomiting in 4 located at frontal and posterior fosse. Delay in referral was seen in 4, 2 each in frontal and temporoparietal region and increase in size of hematoma was seen in 2 located at frontal region as shown in Table 1. There was 2 deaths and 8 had poor outcome in this group of patients. 134 patients were managed conservatively as shown in Table 2. All patients had GCS $>12$ except 12.6 patients died, all had associated intracranial lesions. There were 76 clots $<10 \mathrm{ml}, 64$ of them were located in the temporoparietal region and there were 58 clots $>10 \mathrm{ml}, 8$ were located at temporoparietal region and 22 were located at fronto- temporal or frontal region as shown in Table 2. 106 cases were operated upon by craniotomy. 62 were operated upon immediately and 44 were operated upon as delayed. Out of those operated immediately, 14 frontal, 6 temporal, 16 parietal, 4 occipital and 8 temporoparietal clots were $>25 \mathrm{cc}$ and the GCS was $<12$ in 40 , abnormal pupillary signs in 10, hemiparesis in 2 and 6 were located in the temporal region. Four patients died, two having temporal and the other two temporoparietal clot. 14 patients had clot $<25 \mathrm{ml}, 4$ each in frontal and temporal, 2 each in parietal, occipital and temporoparietal region, all had good outcome, as shown in Table 3.

\section{Discussion}

The history of operative intervention of the ailment related to skull dates back to Master Surgeon Sushrutha which are mentioned in "Sushrutha Samhita" ( 800 B. C.). Hippocrates recommended that the cranium be perforated when injuries might be followed by serious consequences such as the extravasation of blood. By trephining patients for EDH and evacuating the blood resulted in the recovery of the patients during 18th century [4], Celsus advised waiting until untoward symptoms appeared before operating. Operated mortality was high during early years of 20th century [5], There was unrecognized high lethality in comatose patients due to traumatic acute EDH with no difference in outcome with regard to gender, mode of injury, or the presence of or the absence of contusion or shift of midline in the CT scan. The motor score immediately before the operation was the most powerful preoperative predictor of outcome. So it was recommended to immediate evacuation of EDH i.e. when they are first noted on the CT scan rather than waiting for clinical motor deterioration [6].

Until 1980, only a few delayed EDH were recorded, when angiography was used to make the diagnosis. The interval between injury and development of clinical signs is an important factor in determining the better prognosis than the acute. Most sub acute hematoma arises from venous, often combined, low tension sources of bleeding. The importance of recognizing gradual neurological deterioration and performing craniotomy in these patients is rewarding [7].

CT diagnosis of hematoma before the development of signs of depressed cerebral functions has reduced morbidity and mortality but disability is the greatest risk for a patient whose sub-acute hematoma is evacuated late [8]. In the case of chronic EDH, there is membranes development and liquification of the clot 
Traumatic extradural hematoma - our comparative experience between conservative and surgical

which may permit drainage of such collections through twist drills and burr holes. The time from development and the neuro-imaging changes on CT and MRI can suggest the age and nature of the clot and thus permit timing of surgery so that drainage may be accomplished with a minor procedure [9], In the present study 44 patients $(25 \%)$ out of 178 deteriorated in course of conservative treatment (group B2) and required neurosurgical interventions. Various reasons responsible for delayed interventions are tabulated in Table 1. Of these 44 patients only $8(18 \%)$ had poor outcome and $2(4.5 \%)$ died. There were 134 cases which were treated conservatively only with poor outcome in $12(9 \%)$ and mortality rate of $4.47 \%$ (6 cases) only.

Very good results are obtained due to CT scan because surgery can be preformed quickly in patients in better neurological condition. Repeated CT scans are indicated in patients with worsening symptoms who may have an unusual delayed intracranial hematoma. In this study 362 patients where operated upon immediately after CT scan with poor outcome in only four patients. Two patient died and the other (with multiple brain contusions) was permanently disabled. There is no question that to withhold a CT scan of a patient who does not yet have a focal neurological deficit. Jamieson during 1969 stressed that; one must prevent appearance of classical clinical picture [10].

\section{Conservative management}

Sophisticated care of head injury patients in the emergency department does not demand sophisticated knowledge of neurosurgery. Instead it depends upon meticulous attention to the fundamental principles of resuscitation, prevention of secondary insult to brain that can further injure the traumatized brain. For many years it has been known that some patients can tolerate the presence of an intracranial hematoma and will recover even if it is not surgically removed. Cases of EDH, sometimes of considerable size that were not surgically treated were regularly reported in the literature. Traumatic epidural hematomas that are minimally symptomatic do not require surgical intervention. Despite the well performed clinical studies and the experience of many neurosurgeons using prompt evacuation of $\mathrm{EDH}$, there have been number of reports suggesting non-operative management of selective EDH [11-18]. The use of CT scan in head trauma revealed a new class of EDH patients who may be treated conservatively. Such patients should be monitored with frequent neurological examinations and regular serial CT scans to demonstrate resolution of the hematoma and associated shift. With such clinical and radiographic monitoring, a subgroup of patients with acute EDH is detected in whom a return of normal mental status will follow loss of consciousness and in whom spontaneous resolution of their hematoma will occur [19]. In the past these hematoma were occasionally discovered even some weeks after the injury during the course of neurosurgery for other reason namely dural plastic surgery of ACF. Some expressed doubts concerning the need to remove EDH in patients affected by subjective disorders only and without neurological deficits [20], One of the several mechanisms to explain the resorption of the hematoma was the transfer of the clot into the epicranial space through the skull fracture [21].

In some studies the size of the hematoma, rather than its location, the degree of midline shift were the most influential in deciding in favor of surgical treatment in asymptomatic significant EDH [22, 23]. But temporal location of EDH with heterogeneous density in patients whose CT scan was performed $<6$ hours after trauma had a higher risk of hematoma growth and thus should be treated surgically [24]. In our study involving 134 patients managed conservatively, out of 76 clots $<10 \mathrm{ml}$, only 6 have poor outcome, 4 were located at temporoparietal reaion and 2 at fronto temporal clot size $>10 \mathrm{ml}$, six patients had poor outcome, 2 with occipital hematoma and 4 with temporoparietal clots and there were 6 deaths, 4 had temporoparietal clots and 2 with occipital clot. All patients with frontal and occipital hematoma having small size had good outcome. 22 patients out of 46 patients with temporal and temporoparietal location of the EDH as compared to only 22 out of the rest 132 patients on conservative management needed be converted to surgical management which was statistically significant ( $\mathrm{p}<0.002$ ). 122 patients had GCS $>12$, only 12 patients had GCS $<12$. It is stressed that small size < $10 \mathrm{ml}$, GCS $>12$ and locations other than temporal area may be considered as the criteria for conservative management.

\section{Tables}

Table No.1 Details of cases converted from Conservative to Surgical Management

\begin{tabular}{|c|c|c|c|c|c|c|}
\hline Site & Case no & Size & Case No. & \multicolumn{2}{|c|}{ Outcome } & \multirow[t]{2}{*}{ Deaths } \\
\hline & & & & Good & Poor & \\
\hline Frontal & 8 & $\begin{array}{l}<25 \mathrm{ml} \\
>25 \mathrm{ml}\end{array}$ & $\begin{array}{l}4 \\
4\end{array}$ & $\begin{array}{l}4 \\
2\end{array}$ & $\begin{array}{l}0 \\
2\end{array}$ & $\begin{array}{l}0 \\
0\end{array}$ \\
\hline Parietal & 6 & $\begin{array}{l}<25 \mathrm{ml} \\
>25 \mathrm{ml}\end{array}$ & $\begin{array}{l}2 \\
4\end{array}$ & $\begin{array}{l}2 \\
4\end{array}$ & $\begin{array}{l}0 \\
0\end{array}$ & $\begin{array}{l}0 \\
0\end{array}$ \\
\hline Temporal & 6 & $\begin{array}{l}<25 \mathrm{ml} \\
>25 \mathrm{ml}\end{array}$ & $\begin{array}{l}4 \\
2\end{array}$ & $\begin{array}{l}4 \\
2\end{array}$ & $\begin{array}{l}0 \\
0\end{array}$ & $\begin{array}{l}0 \\
0\end{array}$ \\
\hline Temporoparietal & 18 & $\begin{array}{l}<25 \mathrm{ml} \\
>25 \mathrm{ml}\end{array}$ & $\begin{array}{l}0 \\
18 \\
\end{array}$ & $\begin{array}{l}0 \\
12 \\
\end{array}$ & $\begin{array}{l}0 \\
6\end{array}$ & $\begin{array}{l}0 \\
2\end{array}$ \\
\hline
\end{tabular}


Traumatic extradural hematoma - our comparative experience between conservative and surgical

\begin{tabular}{|l|l|l|l|l|l|l|}
\hline Occipital & 4 & $<25 \mathrm{ml}$ & 0 & 0 & 0 & 0 \\
& & $>25 \mathrm{ml}$ & 4 & 4 & 0 & 0 \\
\hline Posterior Fossa & 2 & $<25 \mathrm{ml}$ & 2 & 2 & 0 & 0 \\
& & $>25 \mathrm{ml}$ & 0 & 0 & 0 & 0 \\
\hline Total & 44 & & 44 & 36 & 8 & 2 \\
\hline
\end{tabular}

Table No.2 Cases treated by Conservative means

\begin{tabular}{|l|l|l|l|l|l|l|l|}
\hline Site & Case no & \multicolumn{2}{l|}{ Size } & Case no. & Outcome & \multirow{2}{*}{ Deaths } \\
\hline \multicolumn{2}{|l|}{} & \multicolumn{2}{l|}{ Good } & Poor & \\
\hline Frontal and fronto-temporal & 46 & $<10 \mathrm{ml}$ & 24 & 22 & 2 & 0 \\
& & $>10 \mathrm{ml}$ & 22 & 22 & 0 & 0 \\
\hline Parietal & 46 & $<10 \mathrm{ml}$ & 24 & 24 & 0 & 0 \\
& & $>10 \mathrm{ml}$ & 22 & 22 & 0 & 0 \\
\hline Temporoparietal and temporal & 22 & $<10 \mathrm{ml}$ & 14 & 10 & 4 & 0 \\
& & $>10 \mathrm{ml}$ & 8 & 4 & 4 & 4 \\
\hline Occipital & 16 & $<10 \mathrm{ml}$ & 10 & 10 & 0 & 0 \\
& & $>10 \mathrm{ml}$ & 6 & 4 & 2 & 2 \\
\hline Occipital & 4 & $<10 \mathrm{ml}$ & 4 & 4 & 0 & 0 \\
& & $>10 \mathrm{ml}$ & 0 & 0 & 0 & 0 \\
\hline Total & 134 & & 134 & 122 & 12 & 6 \\
\hline
\end{tabular}

Table No. 3 Details of cases treated by immediate surgery

\begin{tabular}{|l|l|l|l|l|l|l|l|}
\hline \multicolumn{9}{|l|}{ Site } & Case no & Size & Case No. & Outcome & Deaths \\
\hline \multicolumn{2}{|l|}{} & 18 & $<25 \mathrm{ml}$ & 2 & Good & Poor & \\
\hline Parietal & & $>25 \mathrm{ml}$ & 16 & 2 & 0 & 0 \\
& 10 & $<25 \mathrm{ml}$ & 4 & 16 & 0 & 0 \\
\hline Temporal & & $>25 \mathrm{ml}$ & 6 & 4 & 0 & 0 \\
& & $<25 \mathrm{ml}$ & 4 & 4 & 2 & 2 \\
\hline Frontal and fronto temporal & 18 & $>25 \mathrm{ml}$ & 14 & 4 & 0 & 0 \\
& & $<25 \mathrm{ml}$ & 2 & 2 & 0 & 0 \\
\hline Occipital & 6 & $>25 \mathrm{ml}$ & 4 & 4 & 0 & 0 \\
\hline Temporal parietal & & $<25 \mathrm{ml}$ & 2 & 2 & 0 & 0 \\
& 10 & $>25 \mathrm{ml}$ & 8 & 6 & 2 & 2 \\
\hline Total & & & 62 & 58 & 4 & 4 \\
\hline
\end{tabular}

\section{Conclusions}

In 134 patients continued conservatively, out of 76 clots $<10 \mathrm{ml}$, only 6 have poor outcome and none of the patient died. Out of 58 patients with clot size $>10 \mathrm{ml}, 6$ patients had poor outcome and there were six deaths. All patients with frontal and occipital hematoma having small size had good outcome. 122 patients had GCS $>12$ only 12 patients at GCS $<12$. Twenty two patients out of 46 patients with temporal and temporoparietal location of the $\mathrm{EDH}$ as compared to only 22 out of the rest 132 patients on conservative management needed to be converted to surgical management which was statistically significant $(\mathrm{p}<0.002)$. It is stressed that small size $<10 \mathrm{ml}$, GCS $>12$ and locations other than temporal area are the criteria for conservative management. 44 patients out of 178 were needed to be treated surgically during the course of conservative management due to neuro-deterioration, increase in size of hematoma on CT, bradycardia, hemiparesis, pupillary abnormalities, delay in referral and only $18 \%$ had poor outcome. A strict vigilance is to be kept for various reasons mentioned above and patients should be subjected to repeat CT scan. 58 patients out of 62 who were early diagnosed and immediately operated upon had good outcome, which shows the successful results of early diagnosis and intervention. Jannett and Bonds criteria measured outcome according to Glasgow outcome score, 12 patients died 6 each in operative and conservative group. 216 patients out of 240 had good outcome. It is stressed that a group of patients can be treated conservatively without undergoing surgical intervention provided a strict vigilance is required to assess clinically supplemented by repeat CT scan. 


\section{References}

[1] Bell C (1816) Surgical observations. Longman, Hirst Rees Edv Arrie and Brown: 466

[2] Frankhauser H, Kiener M (1982) Delayed development of extradural hematoma. Acta Neurochir (wien) 60:29-35

[3] Jennet B, Bond M (1975)Assessment of outcome after severe brain damage, a practical scale. Lancet 1: 480-484

[4] Hill J (1772) Case in surgery particularly of cancers and disorders of the head from external violence and observation. J Bal four, Edinburgh: 263

[5] Munro D, Maltby GL (1941) Extradural hemorrhage. Ann Surg 113(2): 192-203

[6] Seeling JM, Marshal LF, Tautan SM, et al. (1984) Traumatic acute EDH, unrecognized lethality in comatosed patients. Neurosurg 15:617-620

[7] Pozzati E, Frank F, Frank G, et al. (1980) Subacute and chronic EDH, A study of 30 cases. J Trauma 20(9):795-799.

[8] Zuccarello M, Fiore DL, Pardatscher K, et al. (1983) Chronic EDH. Acta Neurochirurgica 67:57-66

[9] Kaufman HH, Herschberger J, Kopitnik T, et al. (1992) Chronic EDH, Indications for surgery. Br J Neurosurg 6:359-364

[10] Jamieson KG, Yelland J DN (1968) Extradural and subdural hematoma. Report of 167 cases. J Neurosurg 299:13-23

[11] Aoki N (1981) Rapid resolution of acute epidural hematoma. Report of 2 cases. J Neurosurg 54:258-261

[12] Tochio H, Waga S, Tashiro H, et al. (1984) Spontaneous resolution of chronic epidural hematomakTleport of 3 cases. Neurosurg 15:96-100

[13] Illingworth R, Shawdon H (1983) Conservative management of intracranial extradural hematoma presenting late. J Neurol Neurosurg Psychiatry 46:558-560

[14] Pang D, Horton JA, Henon JM, et al. (1989) Non-surgical management of extradural hematomas in children. J Neurosurg 59:958-971

[15] Tuncer R, Kazan S, Ucar T, et al. (1993) Conservative management of epidural hematomas. Prospective study of 15 cases. Acta Neurochir (Wien) 121:48-52

[16] Bullock R, Smith RM, Van Dellen JR (1985) Non-operative management of extradural hematoma. Neurosurg 16: 602-606

[17] Ceylan S, Kuzeyli K, Ilbay K, et al. (1992) Non-operative management of acute extradural hematoma in children. J Neurosurg Sci 36:85-88

[18] Chen TY, Wong CW, Chang CN, et al. (1993) The expectant treatment of asymptomatic supratentorial EDH. Neurosurg 32(2): 176-179

[19] Weaver D, Pofereskin L, Jane JA (1981) Spontaneous resolution of EDH. Report of two cases. J Neurosurg 54: 248-251

[20] Trowbridge WV, Poster RW, French JD. (1954) Chronic EDH. Arch Surg 69:324-330

[21] Tuncer R, Acikbas C, Ucar T, Kazan S, Karasoy M, Saveren M (1997) Conservative management of extradural haematoma. Effects of skull fractures on resorption rate. Acta Neurochirurgica 139(3):203-207

[22] Cook RJ, Dorsch NW, Feamside MR, et al. (1988) Outcome prediction in EDH. Actaneurochir (Wein) 95(3-4):90-94

[23] Servadei F, Faccai G, Rocella P, et al. (1989) Asymptomatic EDH, results of a multicenter study of 158 cases in minor head injury. Acta Neurochir (Wein) 96:39-45

[24] 24. Bezircioglu H, Ersahin Y, Demircivi F, et al. (1996) Nonoperative treatment of acute extradural hematomas: analysis of 80 cases. J Trauma 41:696-698. 